\title{
2 \\ Staging a Caring Atmosphere: Child-Friendliness in Barnahus as a Multidimensional Phenomenon
}

\section{Kari Stefansen}

\section{Introduction}

In 2011-2012, I was part of a research team that evaluated the Norwegian Barnahus model (Bakketeig et al. 2012; Stefansen et al. 2012). For the purpose of the evaluation, we visited six Barnahus around the country. While the premises differed somewhat in size, layout and design, we were struck by the general welcoming feel of all the Barnahus. We could sense that great care had been taken to soften the impression of a formal and "adult" space. Furniture would often be bright colours, and there would be pillows and blankets, and soft rugs on the floor. In halls and other common areas, plants and pictures were used for decorative purposes. Some places had stuffed animals sitting around, and there might be a radio on with the sound turned low. Toys, books and a TV set were available in the designated waiting areas, and sometimes, there was a game

K. Stefansen $(\bowtie)$

Norwegian Social Research, Oslo and Akershus

University College of Applied Sciences, Oslo, Norway

e-mail: kari.stefansen@nova.hioa.no 
console and a massage chair. All the Barnahus we visited were clean and tidy, and the furniture and materials seemed to be of high quality. The picture below (Photo 2.1) is an apt illustration.

The nice interiors of the Barnahus are the institutional settings for children's testimony about difficult and possibly traumatising experiences of violence and sexual abuse, which sometimes involve close family members as the perpetrators. Prior to the establishment of Barnahus in Norway, children were summoned to such interviews either at the local police station or courthouse, and few if any special measures were taken to reduce the stress and possibly re-traumatising effect of participating in the legal process (Bakketeig et al. 2012, 121). The Barnahus premises clearly represent a very different physical environment for children's testimony. Against this background, I will highlight and discuss the "aesthetic-spatial support" (cf. Bjørnholt 2014) that the Barnahus locality, layout and design may represent for children and families. What is it meant to communicate, and how do children and their caretakers perceive it?

Part of the background to my analysis relates to discussions at the European level of the importance of child-friendly justice and the role of child-friendly environments in this respect (see Council of Europe

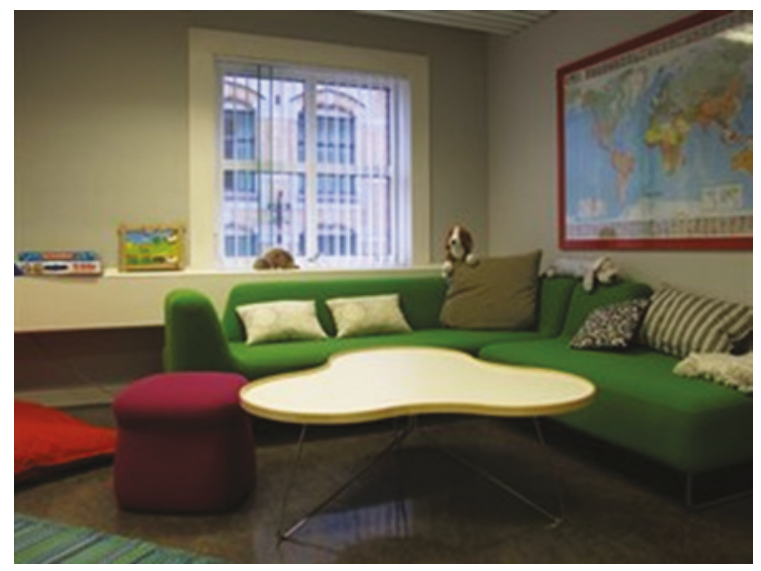

Photo 2.1 Waiting area, Oslo Barnahus. Source www.statensbarnehus.no 
2010; Kaldal 2015). My aim is to further the scholarly discussion on this topic: What does it mean to provide a child-friendly environment for children's testimony in cases involving violence and sexual abuse? Is child-friendliness related to aesthetics alone or also to other dimensions of the Barnahus activity?

It is worth mentioning here that concern has been voiced about the possible negative consequences of child-friendly aesthetics in Barnahus. In the final report from a comprehensive evaluation of the Swedish Barnahus model, Kaldal and colleagues (Kaldal et al. 2010, 146) concluded that Barnahus premises should be child friendly, but not invite to play and activity. In their opinion, Barnahus is a place for investigations and this should be reflected in the design of the premises: "It is certainly not wrong to make the setting nice and welcoming, but if overstated there is a risk of it being an over-stimulating environment for the child. The environment should in other words be neutral, preferably warm and caring, but not stimulating for play and fantasy" (p. 146, my translation, italics in original).

As part of the evaluation of the Norwegian Barnahus model (Bakketeig et al. 2012), lawyers and judges were interviewed. Some of the lawyers voiced concern that the informal atmosphere of the Barnahus in some ways contradicts the formal procedure that the investigative interview represents. Some of the judges expressed similar views. Others, however, took the opposite approach and argued that the Barnahus localities represent "safe environments and (...) a great place to interview children" (quote from Bakketeig et al. 2012, 76, my translation). These differing views suggest that the meaning of childfriendliness within the Barnahus model, and particularly the role of the material, is far from fixed. In my opinion, these differing views make an interesting background for the exploration of the layers of meaning that the material aspect of the Barnahus may hold for children and the professionals who are involved in Barnahus work.

In the following, and to facilitate discussion of the aesthetic-spatial element of child-friendliness, I will present two empirical analyses. First, I will explore how the notion of child-friendliness was articulated in key documents that were produced as part of the process of implementing 
Barnahus in Norway. I will then explore the views of children and adult caretakers who have visited Barnahus in Norway as a result of a suspected crime-about the Barnahus idea in general, and the physical environment in particular. I follow the lead of Blundell-Jones (2014) who argues that buildings and interiors do not have fixed meanings, but offer users a framework for interpretation. It follows that different users may read the physical fabric of a space differently. This part of the chapter draws on survey data from children and adult caretakers.

\section{Staging Atmospheres: Articulations of Child-Friendliness in Key Texts ${ }^{1}$}

To follow the way that child-friendliness was discussed in the implementation phase of Barnahus in Norway, I have analysed a sample of key texts produced between 2004 and 2010. The sample includes texts written by NGOs, politicians and working groups at both the state level and local level. The documents can be seen as carriers of ideas that circulate in an ongoing discussion about child-friendly justice: What are the needs of victimised children during the legal process and beyond, and how should the Barnahus localities be arranged to accommodate them?

The idea of establishing the Barnahus model in Norway was introduced in a report published in 2004 by Save the Children Norway (Skybak 2004). In the report, the Barnahus model is described as a place that is " $(\ldots)$ child-friendly decorated with a child-oriented atmosphere that creates a sense of security for visiting children" (p. 6). In a later passage, what it means to create a sense of security for children is elaborated further: "(...) the Barnahus will be designed on children's terms with toys, small furniture, children's pictures on the walls, and colour. It will not have an institutional or office feel that makes the child feel insecure and alienated" (p. 15). The inspiration for the proposal was taken from the Barnahus in Iceland. The Icelandic Barnahus is described in the report as "a child-friendly house", and it is emphasised that it is located in an anonymous house in a residential area. According to the report, these surroundings mean that Barnahus is not 
scary and unfamiliar to children, in the way that public offices, hospitals, police stations and courts can be.

In this report, then, child-friendliness is linked primarily to children's feelings of safety. Safety is further connected to feelings of being in the right place, a place for children, and the presence of children's furniture and toys will communicate this. The suggestion to localise Barnahus outside established institutions follows from this construction of safety. The idea expressed here could be understood as an effort to stage what Edvardsson et al. (2005) define as a "supportive care setting" (related to nursing). They conceptualise supportive care settings as settings where patients are "sensing an atmosphere of ease" which facilitates the experience of being in familiar and safe surroundings. This further entails a feeling of "being seen, acknowledged and cared about" (p. 344).

Following the report from Save the Children, a private member motion for a pilot project with Barnahus in Norway was suggested in Parliament. ${ }^{2}$ In the motion, Barnahus is described in a way that clearly links to the Save the Children's report and the core idea about safety, as achieved through "a neutral, child-friendly environment" (p. 2) in which investigative interviews and medical examinations can take place. The word neutral in this context refers to Barnahus as not linked to formal and possibly alienating institutions, such as hospitals, police stations and courts. A child-friendly environment is defined further as a "comfortable, private and child-oriented atmosphere that is secure both in the psychological and physical sense" (p. 3).

The suggestion of a pilot project with Barnahus was discussed in Parliament in March 2005, and the pilot project was recommended. ${ }^{3}$ In a comment on the recommendation, the Standing Committee on Justice said that Barnahus should be designed to accommodate children in all age groups, introducing the idea that child-friendliness is age related. The committee also endorsed the idea of neutral surroundings as essential for achieving child-friendliness. The opposite view that placing the facility in a residential area and away from other ordinary activities such as shopping, and visits to cafes, restaurants and public offices, could underline the child's situation as special, was not mentioned, Research shows, however, that from the perspective of children 
and young people, an out-of-town location for special measures may be perceived as strange (cf. Stanley et al. 2016).

In 2006, the Ministry of Justice and the Police published a report from a ministerial working group on the implementation of a pilot project with Barnahus in Norway (Norwegian Ministry of Justice and the Police 2006). The working group endorsed the idea of a neutral location as part of the child-friendly approach, stating that the Barnahus premises should not be associated with either the police or a hospital. "The locale should not be institutional, and they should as far as possible be anonymous. (...) All rooms should be child-friendly and the waiting room should be equipped for children's well-being. Care must be taken to accommodate children in different ages" (p. 48). The report is inconclusive about the question of placing the Barnahus in a house in a residential area.

In this report, the idea of child-friendliness is expanded to children's well-being in a wider sense. The connection of well-being and how the rooms are "equipped" suggests that children's well-being relates to the activities the premises allow and invite, such as play, relaxation, being entertained or distracted from the issue at hand. Toys and equipment are not only important in the concrete sense, but also in the symbolic sense-they communicate to children that they are children and not only victims (see Olsson and Kläferud, Chap. 3).

From 2007, regional working groups were established to implement pilot projects with Barnahus at seven locations throughout the country. I have looked at the reports from such working groups and particularly the reports from Bergen (2007) and Oslo (2010). The Bergen report was the very first and therefore influential for later reports, and the Oslo report is interesting because it is the most elaborate in terms of discussions about the aesthetic-spatial environment. It also sets the bar high for the material aspect of child-friendliness within the Barnahus model, as I will explain later.

The Bergen report draws on the governmental report in many respects. It states that Barnahus should not be placed in a police station or hospital. It links child-friendliness to "calm surroundings" (p. 15) and mentions special waiting areas equipped for younger children and teenagers, respectively. This report is the first to link child-friendliness 
to the layout of the Barnahus interiors, the placing of rooms with different functions in relation to each other. It states, for instance, that the co-hearing room, the room where the judge and other involved agencies watch the investigative interview via direct video link, should not be placed next to the interview room. In this way, the child will not have to meet all the professionals involved in a Barnahus case prior to the interview. Another theme introduced in this report is the size of the interview room. It should not be too big. The thought behind this is that a small room feels more secure for the child and leads to less distraction. The interview rooms should also accommodate children of different age groups-a statement that also links child-friendliness to age appropriateness in the interview setting. This seems to have become the standard view in Norway. It is common in Norwegian Barnahus to have different interview rooms for young and older children. In interview rooms for the youngest children, the furniture is small and designed for children below school age, while the interview rooms for older children will have "normal" furniture, as illustrated in the pictures below (Photos 2.2 and 2.3).

The sparse decoration of the interview rooms in the pictures above is not mentioned in the working group reports, but is something we see in Barnahus in Norway. The child-friendly décor is reserved for

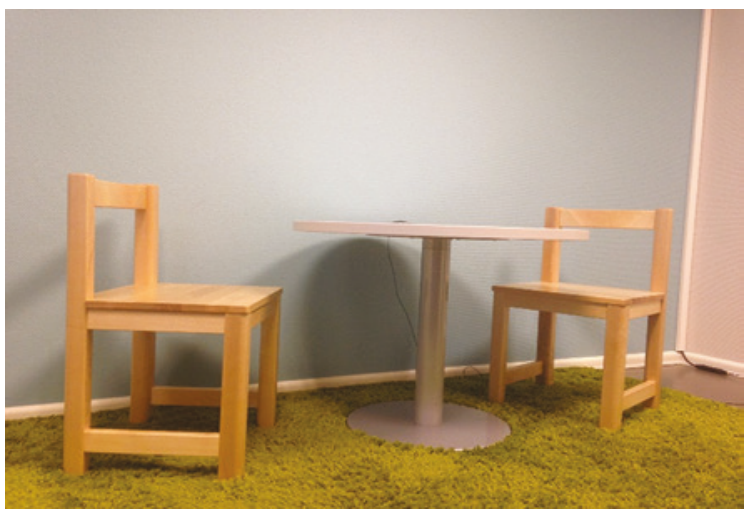

Photo 2.2 Investigative interview room for young children at Sandefjord Barnahus (picture by author) 


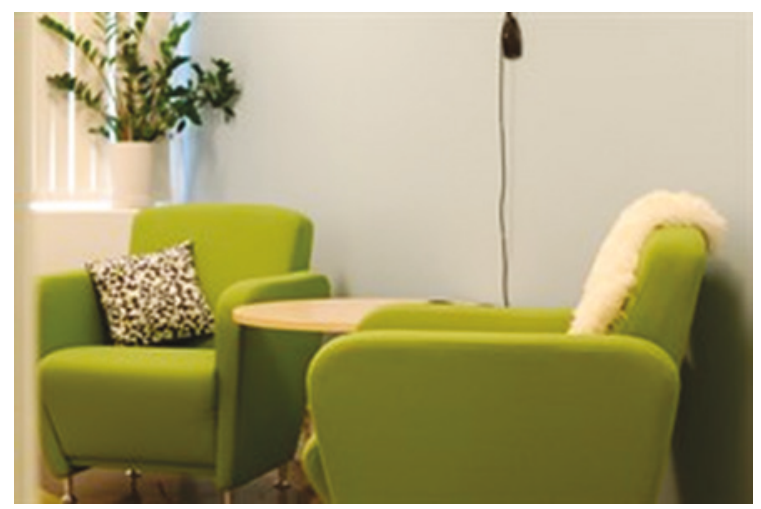

Photo 2.3 Investigative interview room for older children at Oslo Barnahus. Source www.statensbarnehus.no

waiting areas, kitchen, halls and the medical examination room. This use of décor is instructional for the child and suggests that different rooms have different purposes, something children seem to understand (cf. Olsson and Kläferud, Chap. 3). Interestingly, in theories of the therapeutic effect of buildings and interiors, the level of instruction that is built into, for instance, an institution such as a hospital is foregrounded as an important dimension for patient's well-being (Gesler et al. 2004).

In the Oslo report, elements such as light, sound and air quality are introduced, which further broadens the idea of child-friendliness within the Barnahus context. The locale should not only be neutral, accessible, suitable for children of different ages and generally child friendly, but also "bright", able to be soundproofed and have a good air ventilation. These elements add to the list of criteria for child-friendliness and set a high physical standard for Barnahus localities. The report also introduces suggestions from a professional interior decorator who was commissioned to suggest a design concept for Oslo Barnahus. This is an example of a professionalisation of the process of making the Barnahus localities child friendly, as the quote below illustrates:

All painted planes have light colours and fabrics for chairs are chosen according to a holistic plan for the locale. Desks and bureaus are either 
white or birch and the fabrics are one-colored in blue and green tones. Emphasis is put on creating nice and friendly locations - something which is reflected in pictures and carpets (Oslo Police District 2010, 90).

What is also evident here and in the concrete implementation of Barnahus in Norway is that child-friendliness in time came to mean a child-friendly layout and interiors, and that the idea of establishing Barnahus as a separate house in a residential area was abandoned. Child-friendliness became an issue to be solved within mostly office buildings. In an analysis of the relationship between architecture and pedagogy in Waldorf education, Bjørnholt (2014) discusses how childcenteredness can be achieved through the manipulation of the physical environment and asks whether "the act of modifying and transcending the limitations of the given building structures may be as important as the architecture" (p. 120). The same question could be asked in relation to Barnahus.

In summary, aesthetic-spatial considerations were high on the agenda throughout the process of establishing the Barnahus model in Norway. The idea of the aesthetic-spatial dimension of child-friendliness that was launched in the early texts about Barnahus was linked to safety as a primary need for children who have been victimised. Safety was furthermore understood as linked to a feeling of being welcome as a child, and not a victim, hence the weight put on toys, décor and equipment that invites children to play or relax. One of the key ideas was also that any association with a formal institution-either police or hospital-would compromise the atmosphere of safety.

The concept of atmospheres is difficult to define, but can be understood as "a sensuous 'something' that takes place between things and people. Atmospheres may be ontologically difficult to grasp or contain, yet they play an important role in ordering spaces and social life" (Bille 2015, 257). The concept of making or "staging atmospheres" (Bille 2015; Bille et al. 2015; Böhme 2013) through locality and symbolic décor captures the thinking about child-friendliness in the texts referred to above. Staging atmospheres relates to "how people actively try to shape experiences and moods of selves and others through organizing objects, bodies and spaces" (Bille et al. 2015, 33). 
In the key texts referenced above, there is no mention of children's voices. The ideas of child-friendliness that are discussed are all articulated by adults. The Barnahus is thus not an "invited space" in the sense that Gaventa (2006) writes about it, meaning a space that service users are invited to co-create by those in authority (see also Stanley et al. 2016). A key question is whether the thoughtful staging or orchestration of child-friendliness in the Norwegian Barnahus works - in the sense that children and accompanying caretakers feel welcomed, seen and cared for, key features of "supportive care settings" (Edvardsson et al. 2005).

\section{Perceived Atmospheres: Children and Caretaker Experiences of Barnahus ${ }^{4}$}

How do children and accompanying caretakers experience a day at the Barnahus, the atmosphere and the premises? Do they feel seen, welcome and safe? To explore these questions, I will draw on two surveys from 2012 conducted among children (aged 10 years+) and caretakers who visited six different Barnahus in Norway over a 2-month period. A total of 123 children and 198 accompanying adults answered questionnaires, setting the response rates at 62 and $69 \%$, respectively. ${ }^{5}$

The questionnaires included questions about the day at the Barnahus, how the child and caretaker were guided through the process with the investigative interview, medical examination and the subsequent consultation with the Barnahus staff. We included questions about the investigative interview and medical examination, and about the waiting area, but refrained from asking about the child's experience with violence or sexual abuse. Most questions had fixed answers, but we also included some open-ended questions where the participants could write their answers in their own words. In the results section, we will present patterns related to both types of questions.

As I will explain in the following, children who visit Barnahus generally appreciate the atmosphere of the place, and the physical environment seems to play a key part in their positive evaluation (see also Rasmusson 2011). 
It is important to take into account that for most children and caretakers, Barnahus is an unfamiliar place: they have not been there before and very few have talked with the police prior to the visit. Given the reason for the Barnahus visit, it is not surprising that children are anxious before the visit. In the survey, close to $60 \%$ of both children and parents indicated that they had been anxious (stated "yes, very" or "yes, somewhat" to a question about anxiety). Cross-tabulation of the answers by parents and the child's age revealed that it was more common for children aged 10 years or older $(77 \%)$ to be anxious compared to younger children (43\%).

We asked the children to describe in their own words why they were anxious. Almost half of the children $(n=51)$ replied. Most answers fell into three broad categories: The majority answered that they were anxious about talking about what had happened and about talking to the police, some wrote about being afraid to say something wrong and that they feared the response from the police, and some wrote about not knowing what to expect from the day at the Barnahus. Here are some typical quotes from the latter category:

- I thought it would be scary there (Boy, 10-12 years).

- I had not been here before (Girl, 10-12 years).

- I did not know what they would ask me (Girl, 13-15 years).

The insecurity that the children conveyed in these answers is an apt reminder of the need to create a safe and welcoming space at the Barnahus. The children's and caretakers' answers to the questionnaire as a whole suggest that their stay was better than the children feared. In the direct question about this issue, the majority of both children $(66 \%)$ and caretakers (52\%) indicated that the stay at the Barnahus had been better than expected and very few indicated that the stay had been worse ( $4 \%$ children, 3\% caretakers). Among the children, 30\% answered that the stay had been as they expected. The corresponding number of caretakers was $45 \%$.

We also asked the children to explain in their own words what they thought about the Barnahus overall. Their answers suggest that children's feeling of safety relates to the child-friendliness of the Barnahus 
model in a broad sense, and that the aesthetical-spatial dimension is an integral part of this.

At the very end of the questionnaire, the children were encouraged to write a general comment: "Here you can describe what you think about the Barnahus all in all." Close to two-thirds of the children $(n=78)$ wrote a comment. A few were negative and some communicated that they thought that the Barnahus was ok-perhaps taking a neutral position. The majority of answers, however, were positive. Three themes emerged among the positive answers. A first theme related to the staff at the Barnahus and their approach to the children:

- I think it is a good place to talk about the experience and there were really nice people there (Girl, 13-15 years).

- Really good people. They really do everything to help you! (Girl, 13-15 years).

A second theme relates to the Barnahus model as a good idea for children in their situation and a good place to be:

- I think it is a really good house (Boy, 10-12 years).

- I think it is good what you do here (Boy, 16-18 years).

- The Barnahus is a good place for children who want to talk about how they feel (Girl, 10-12).

A third theme relates to the locale and the possibilities for both relaxation and activity:

- I like the Barnahus because it is nice there. Nice and decorated rooms (Boy, 13-15 years).

- That it is a nice and calm place. I also think the staff here is nice (:) (Girl, 10-12 years).

- I liked the toys (Boy, 10-12 years).

- It is good to have food and drinks and activities while you wait (Boy, $13-15$ years). 
The three themes were represented at all the Barnahus in the study, which suggests that even where there are differences in routines, decoration and qualifications among the Barnahus (Stefansen et al. 2012), they all managed to convey child-friendliness to visiting children. This also suggests that children's sense of an "atmosphere of ease" (Edvardsson et al. 2005) at the Barnahus, while connected to the actual layout or décor, routines, food and drinks, toys and so on, also, or perhaps mostly, relates to the effort they sense has been taken to "soften" the experience of meeting the police and talking about very difficult experiences.

The most concrete expression of the effort that they sense has been made is perhaps the waiting room area. We asked both children and adults caretakers to indicate whether they liked the waiting room or not. More than half of the children (53\%) and two-thirds of the caretakers $(65 \%)$ answered yes, very much. Very few, and only children, indicated that they did not like it $(6 \%)$. Cross-tabulation showed that adults who accompanied younger children were more positive than adults who accompanied older children. This accords with Rasmussen's (2008) qualitative study of Swedish Barnahus. Rasmussen interviewed 12 children of different ages, and some of the teenagers said that the Barnahus was equipped mainly for younger children; it felt childish. The children who participated in our study were asked to describe why they liked the waiting area or not. Three-quarters $(n=92)$ answered the question. A large majority described what they liked about the premises. Rasmussen's finding that teenagers felt that the Barnahus was too childish was not dominant in our sample. Only a few children voiced this opinion. Some older children even said that they valued the fact that the premises were suitable for younger children (also):

- The waiting room was nicely decorated, and young children would feel comfortable there. The woman who worked there was nice and easy to talk to. The room had a good energy, and it was not so big, so that the client feels safer (Girl, 13-15 years).

The remaining answers can be sorted into three broad categories: one typical answer was that the waiting area was nice and cosy. I take this to refer to the general feel or atmosphere of the room: 
- It was big and nice and that is why I like the waiting room (Boy, 13-15).

- It is nice and very well suited and consoling for children who are struggling a bit (Girl, 13-15).

- It has nice furniture, drinks and a lot of cookies. Really cosy here! There is nothing negative about this room (Girl, 13-15 years).

Another typical answer related to the fact that children could do things in the waiting room-they did not have to sit passively and wait:

- There was a lot of toys here and that was nice. It's lots of things to do (Girl, 10-12 years).

- I like the waiting room because there are lots of fun things to do here, for instance play Wii, or relax (Boy, 10-12 years).

- You can do a lot here. I wish my room was like this! (Girl, 10-12 years).

A third quality that the children appreciated was the ability to relax in the waiting area.

- It is nice here, and there are no kids here so it is nice because it is mostly quiet. And I have relaxed and it was good so I really had a good time in the waiting room (Girl, 10-12 years).

- I liked the waiting room because of the [massage] chair. It was really good to sit in it while I relaxed and some of the people who work here talked to my mum so I sat in the chair (Girl, 10-12 years).

Referring to Rasmussen's (2008) study, Åström and Rejmer (2008) argue that children's responses in interviews suggest that they appreciate and notice the colours, toys and furnishing at the Barnahus. From the perspective of the children who participated in the survey on Norwegian Barnahus, child-friendliness is also connected to the activities that the waiting area invites and the choice between relaxation and play or entertainment. These possibilities are important in both the concrete and symbolic sense; they offer children a sense of agency and they can choose the level of activity that suits them in the situation. 
In summary, children and caretakers see the Barnahus premises as welcoming and consoling in a difficult situation. They sense an "atmosphere of ease" (Edvardsson et al. 2005) at the Barnahus_-across differences between Barnahus in actual layout, design and routines from the staff. The feel of the space seems to calm or distract the children, who in many cases are anxious about meeting the police and talk about their experiences with violence or sexual abuse.

The aesthetic-spatial dimension can be analytically separated as a core dimension of child-friendliness, but on the level of experience, this dimension blends in with the holistic approach to child-friendliness that also includes welcoming routines, the routines for the stay and the meeting with the police interviewer and other professionals at the Barnahus. Children's experiences point to how "place is constructed through relationships between people as well as through the physical environment" (Stanley et al. 2016, 86).

\section{Concluding Thoughts}

Barnahus was introduced in Norway as a means to support child victims of violence and sexual abuse during the legal process and to make sure that children's needs for psycho-social support and treatment were met. In the documents I have analysed, the importance of childfriendly premises is linked primarily to Barnahus as the institutional setting for the legal process. How child-friendliness could be achieved in the Barnahus setting was high on the agenda in the implementation process and revolved around the intent to create a child-friendly atmosphere where children can feel safe because they are seen as children and not (only) as victims of violence or sexual abuse. As the discussion proceeded, the idea of child-friendliness evolved to encompass the quality of the building, colour schemes and layout of the locale. Survey data from children and caretakers who had visited Barnahus as the result of a suspected crime show that the Barnahus premises is understood as welcoming and caretaking - and thus as child friendly. The analysis suggests that this is possible to achieve when Barnahus is placed in various types of office buildings and not conditioned on 
placement in residential areas as some of the key actors involved in the early discussions argued. Rather, the décor, layout and the interior design and physical quality of the premises transcend the institutional feel of such buildings (cf. Bjørnholt 2014): children understand and appreciate the care that has been taken to make sure that they feel welcome and seen. Drawing on Kolstad's (2001) reflections on the role of beautiful environments, it is possible to argue that the Barnahus setting may increase children's self-esteem, that they feel more valuable because they can identify with the environment they are offered (see also Cold 2003). The careful orchestrating of the Barnahus setting to accommodate children's needs can also be seen as a recognition of people's sensitivity to minor details when they are put in a vulnerable situation (Cold 2015). In this sense, the child-friendliness that permeates the material context of the Barnahus setting in Norway mirrors an idea by the Finnish architect Alvar Aalto, as presented by Pallasmaa (2001), that good design takes people at their most vulnerable as a starting point.

The child-friendly atmosphere of the Barnahus model is not linked to the aesthetic-spatial dimension alone, but is multidimensional (cf. Stanley et al. 2016). It is linked to the way the Barnahus staff behaves, how the day is organised and framed, as well as the layout and aesthetics of the premises, particularly the waiting area. One suggestion is that these dimensions combine to what Holopainen et al. (2014) talk about as a caring encounter (in nursing). They define a caring encounter as a "space of togetherness" based on recognition. One idea then is that a child-friendly environment is a necessary, but not sufficient factor for such a "space of togetherness" to emerge. One important role of the aesthetic-spatial dimension in creating a child-friendly atmosphere within the Barnahus involves how it influences the staff and other professionals that are involved in Barnahus work: the child-friendly environment is a constant reminder for the adults that Barnahus is a place where it is especially important to support the well-being of children. This could perhaps be thought of as a mediated effect of the child-friendly layout and décor: it works through the staff as well as directly on the children. Stanley et al. (2016) point to the same in a study on independent social 
work organisations that deliver services to children in out-of-home care and their families, claiming that

the environment and location of social work services are relevant both for staff and for those who receive services, shaping service perceptions and perceptions of self as well as impacting on communication and relationships between practitioners and children and families (Stanley et al. 2016, 86-87).

My aim for this chapter was to enhance the understanding of the role of the material in achieving a child-friendly atmosphere in the Barnahus setting. The analysis has shown that child-friendliness related to the material can be understood at both a surface and a more extensive level comprising the material quality and layout of the premises in addition to child-friendly décor and artefacts. In the Norwegian Barnahus, child-friendliness related to the material is understood in the latter meaning, as something more than having toys and games available. To achieve and maintain child-friendliness in this meaning is a demanding and quite costly task. The expanded idea of child-friendliness that the Norwegian Barnahus represent in a sense reflects the willingness of the state to provide the necessary resources in the process of implementing Barnahus in Norway, and perhaps also shared cultural norms relating to material standards in the Norwegian or Nordic setting. I would argue that there is a general expectance that material standards should be high in public institutions, such as kindergartens, schools and hospitals. Neumann's (2012) work on the experiences of female prisoners regarding the material aspect of prisons is a relevant reference here. A key point in her analysis is that the meanings of the material aspects of an institution relate to the general material conditions in the specific society. Differences in material conditions in different societies may thus have an effect on how children experience the Barnahus environment. Translated to the Barnahus field, and following Neumann's argument, I would caution against a fixed template for child-friendly environments in Barnahus. I hope, however, to have demonstrated the importance of thinking about the meaning of child-friendliness related to the material environment and of allocating resources to this end. 


\section{Afterword}

During my writing of this chapter, I presented an early version for my research group at NOVA. In the discussion, my colleague Svein Mossige, who is a clinical psychologist, talked about the most important institution for child psychiatry in Norway, Nic Waal's Institute, and explained that it is set in a building from the 1960s, meant to be childfriendly. I was curious about the thinking that had inspired the building and searched for books and articles about the institute. The thinking related to Nic Waal's Institute as presented in these texts makes an interesting parallel and contrast to the thinking about the aesthetic-spatial dimension of child-friendliness related to the Barnahus model. I include a brief introduction to it, also as a reminder of the value of the historical perspective in the exploration of present-day ideas of child-friendliness.

The institute and its founder, Nic Waal, played key roles in the development of child psychiatry as a professional field in Norway from the 1950s and onward (Ludvigsen and Seip 2009). The concrete building that houses the institute is placed on a large detached plot near the city centre and was drawn by architects Lund and Slaatto in 1968 (see Grønvold 1988, 213-217 for pictures and drawings). A key idea behind the building was to recreate some of the mysteries of children's play, writes Nic Waal's son, Helge Waal, in a biography about his mother (Waal 1991). Moe (2003) has also pointed out how the structure of the building, with a central atrium and adjacent towers for treatment rooms, was meant to facilitate a non-institutional feel (see also Grønvold 1988, 213), and also how the high placement of windows throughout the building is linked to ideas of sheltering: the outside world should be kept at a distance to avoid noise and distraction and allow for reflection and dialogue. While there are similarities in the weight put on child-friendliness between Nic Waal's Institute and the Barnahus model, how child-friendliness should be achieved is understood very differently. In Nic Waal's Institute, child-friendliness is linked to the structure of the building, the placement and size of windows and the dimensions of key architectural forms such as the cube (Grønvold 1988, 146), and not to the interior design, as it is in the Barnahus model. 
Interestingly, the structure of the building was also meant to support multi-professional teamwork, a foundational element of the work model at the institute in the first decades (Grønvold 1988; Waal 1958). The idea of the building or locale as a facilitator for multi-professional teamwork is to my knowledge not mentioned in writings about the spatial elements of the Barnahus model. This is somewhat surprising given that Barnahus is essentially a model for collaboration between different professions and agencies. Perhaps, this chapter could also inspire discussion of the role of the material environment for professional work within the Barnahus model.

\section{Notes}

1. All quotes translated by author from the Norwegian language.

2. Private member motion: Dok 8:86, 2003-2004.

3. Recommendation to Parliament from the Standing Committee on Justice: Innst. St. nr. 123, 2004-2005.

4. Original analyses were presented in Stefansen et al. (2012), in Norwegian.

5. There were more girls (57\%) than boys (43\%) among the children. The accompanying adult was usually the mother or other relative $(62 \%)$.

Acknowledgement I am indebted to Margunn Bjørnholt, Ingrid Smette, Susanna Johansson and my colleagues in the Domestic Violence Research Programme at NOVA for inspiring discussions and valuable suggestions on how to improve this chapter.

\section{References}

Åström, Karsten and Annika Rejmer. 2008. Det blir nog bättre för barnen. Slutrapport i utvärderingen av nationell förs̈̈ksverksamhet med barnahus 2006-2007. Lund: Lund University.

Bakketeig, Elisiv, Mette Berg, Trond Myklebust, and Kari Stefansen. 2012. Barnehusevalueringen 2012, delrapport 1: Barnehusmodellens implikasjoner for politiets arbeid med fokus på dommeravhor og rettsmedisinsk undersøkelse. Oslo: PHS Forskning. 
Bergen Police District. 2007. Barnehuset region vest. Bergen Police District: Rapport fra planleggingsgruppen. Bergen.

Bille, Mikkel. 2015. Hazy Worlds: Atmospheric Ontologies in Denmark. Anthropological Theory 15 (3): 257-274.

Bille, Mikkel, Peter Bjerregaard, and Tim F. Sørensen. 2015. Staging Atmospheres: Materiality, Culture, and the Texture of the in-Between. Emotion Space and Society 15: 31-38.

Bjørnholt, Margunn. 2014. Room for Thinking-The Spatial Dimension of Waldorf Education. RoSE-Research on Steiner Education 5 (1): 115-130.

Blundell-Jones, Peter. 2014. Foreword. In Kindergarten Architecture. Space for Imagination, ed. Mark Dudek, vi-x. London: Taylor \& Francis.

Böhme, Gernot. 2013. The art of the stage set as a paradigm for an aesthetics of atmospheres.Ambiances. International Journal of Sensory Environment, Architecture and Urban Space. [Online], http://ambiances.revues.org/315.

Cold, Birgit. 2003. Skoleanlegget som lesebok—synteserapport og fem delrapporter. Trondheim: NTNU, Fakultetet for arkitektur og billedkunst.

Cold, Birgit. 2015. Estetikk, velvære og helse. In Interiørarkitektur ed. Ellen S. Klingenberg, 192-209. Oslo: Scandinavian Academic Press.

Council of Europe. 2010. Guidelines of the Committee of Ministers of the Council of Europe on Child-friendly Justice. Council of Europe.

Edvardsson, David, Per-Olof Sandman and Birgit H. Rasmussen. 2005. Sensing an Atmosphere of Ease: A Tentative Theory of Supportive Care Settings. Scandinavian Journal of Caring Sciences 19 (4): 344-353.

Gaventa, John. 2006. Finding the Spaces for Change: A Power Analysis. IDS Bulletin 37(6): 23-33.

Gesler, Will, Morag Bell, Sarah Curtis, Phil Hubbard and Susan Francis. 2004. Therapy by Design: Evaluating the UK hospital Building Program. Health \& Place 10 (2): 117-128.

Grønvold, Ulf. 1988. Lund \& Slaatto. Oslo: Universitetsforlaget.

Holopainen, Gunilla, and Anne Kasénand Lisbet Nyström. 2014. The Space of Togetherness-A Caring Encounter. Scandinavian Journal of Caring Sciences 28 (1): 186-192.

Kaldal, Anna. 2015. Child Evidence. A Comparative Study on Handling, Protecting and Testing Evidence from Children in Legal Proceedings Within States in the Baltic Sea Region. Report Prepared for Council of Europe. Strasbourg: Council of Europe.

Kaldal, Anna, Johan Beije, Eva F. Diesenand, and Christian Diesen. 2010. Barnahusutredningen 2010. Stockholm: Jure. 
Kolstad, Arnulf. 2001. What Happens if Celeste Becomes an Architect? In Aesthetics, Well Being and Health. Essays Within Architecture and Environmental Aesthetics ed. Birgit Cold, 117-128. London: Ashgate.

Ludvigsen, Kari and Åsmund A. Seip. 2009. The Establishing of Norwegian Child Psychiatry: Ideas, Pioneers and Institutions. History of Psychiatry 20(1): 5-26.

Moe, Einar. 2003. Nic Waals Institutt. Pioner og aktør i norsk barne-og ungdomspsykiatri gjennom 50 år. Oslo: Nic Waals Institutt.

Neuman, Cecilie B. 2012. Imprisoning the Soul. In Penal Exceptionalism? Nordic Prison Policy and Practice, ed. Thomas Ugelvik and Jane Dullum, 139-155. London: Routledge.

Norwegian Ministry of Justice and the Police. 2006. Barnas hus. Rapport om etablering av et pilotprosjekt med ny avhørsmodellfor barn som har vart utsatt for overgrep m.m. Oslo: Norwegian Ministry of Justice and the Police.

Oslo Police District. 2010. Sluttrapport Etablering av Barnehuset Oslo. Oslo: Oslo Police District.

Pallasmaa, Juhani. 2001. The Mind of the Environment. In Aesthetics, WellBeing and Health_Essays on Architecture and Environmental Aesthetics, ed. Birgit Cold, 203-220. London: Ashgate.

Rasmussen, Bodil. 2008. Det är ju inget dagis precis ... Barns och föräldrars upplevelser av kontakter med barnahus. Delrapport 6 i utvärderingen av nationell försöksverksamhet med barnahus 2006-2007. Lund: Lund University.

Rasmusson, Bodil. 2011. Children's Advocacy Centers (Barnahus) in Sweden. Child Indicators Research 4 (2): 301-321.

Skybak, Thale. 2004. Barnas hus—et helhetlig og barnevennlig tilbud til barn som har vert utsatt for seksuelt misbruk. Oslo: Redd Barna.

Stanley, Nicky, Cath Larkins, Helen Austerberry, Nicola Farrelly, Jill Manthorpe, and Julie Ridley. 2016. Rethinking Place and the Social Work Office in the Delivery of Children's Social Work Services. Health \& Social Care in the Community 24 (1): 86-94.

Stefansen, Kari, Tonje Gundersen and Elisiv Bakketeig. 2012. Barnehusevalueringen 2012, delrapport 2. En undersøkelse blant barn og pårørende, samarbeidspartnere, ledere og ansatte. Oslo: NOVA.

Waal, Helge. 1991. Nic Waal Det urolige hjertet. Oslo: Pax Forlag. Waal, Nic. 1958. Teamwork. In Utvalgte faglige skrifter Dr. Nic Waal, ed. AnneMarie Auestad, and Borger Haavardsholm. Oslo: Nic Waals institutt. 
Open Access This chapter is licensed under the terms of the Creative Commons Attribution 4.0 International License (http://creativecommons. org/licenses/by/4.0/), which permits use, sharing, adaptation, distribution and reproduction in any medium or format, as long as you give appropriate credit to the original author(s) and the source, provide a link to the Creative Commons license and indicate if changes were made.

The images or other third party material in this chapter are included in the chapter's Creative Commons license, unless indicated otherwise in a credit line to the material. If material is not included in the chapter's Creative Commons license and your intended use is not permitted by statutory regulation or exceeds the permitted use, you will need to obtain permission directly from the copyright holder. 